\title{
SINALIZAÇÃO ACESSÍVEL PARA O LABORATÓRIO DE ANÁLISES CLÍNICAS
}

\author{
Júlia Santos Sales \\ ASBEC - Centro Universitário Jorge Amado \\ julia.s.sales@hotmail.com \\ Valéria Souza Dórea Garcez \\ ASBEC - Centro Universitário Jorge Amado \\ valeriadorea@live.com
}

\begin{abstract}
Resumo: Através do presente trabalho, pretende-se projetar um sistema de sinalização que facilite o acesso de pessoas com necessidades especiais para um laboratório de análises clínicas, o LAC, que se localiza em uma comunidade carente, em Salvador-Ba. Com isso, objetiva-se que os pacientes do laboratório possam estar integrados ao convívio social, independente das suas diferenças, utilizando os setores de forma autônoma, com liberdade de locomoção e facilidade de orientação, através de uma sinalização adequada as necessidades desse público. As etapas cumpridas ao longo do projeto permitiram o entendimento de como as pessoas com necessidades especiais percebem o ambiente em sua volta e de que forma a sinalização do ambiente daria independência para circulação segura nos setores do LAC. Concluiu-se que embora lugares sem acessibilidade não incomodem indivíduos que não tem necessidades especiais, a eliminação dessas barreiras favorece a todos. Um ambiente acessível oferece qualidade de vida, segurança, interação e boa convivência tanto para as pessoas que possuem algum tipo de necessidade especial, como para quem não possui.
\end{abstract}

Palavras-chave: Sinalização, Acessibilidade, Desenho Universal.

Abstract: In the present work, we intend to design a signage system that facilitates access for people with special needs for a clinical laboratory, LAC, located in a poor neighborhood in Salvador - Bahia. Thus, the objective is that patients in the laboratory may be integrated to social life, regardless of their differences using sectors independently, with freedom of movement and ease of orientation, through appropriate signage needs of this audience. The steps taken throughout the project allowed the understanding of how people with disabilities perceive the environment around them and how the signaling environment to give independence movement in safe sectors of LAC. It was concluded that although places without access not disturbed individuals who do not have special needs, the elimination of these barriers favors at all. Environment offers an affordable 
quality of life, safety, interaction and coexistence for both people who have some kind of special need, and for those who do not own.

Keywords: Signs, Accessibility, Universal Design.

\section{INTRODUÇÃO}

O LAC - Laboratório de Análises Clínicas, localizado no bairro do IAPI, Salvador$\mathrm{BA}$, é responsável por prestar serviços à comunidade local para realização de exames laboratoriais, atendendo um grande número de pessoas com necessidades especiais.

No entanto, o sistema é ineficaz para esse tipo de público, sendo perceptível a dificuldade de leitura espacial do mesmo, que necessita de auxílio para deslocar-se no ambiente. Além disso, há dificuldade de reconhecimento externo do local, que muitas vezes é confundido com uma residência.

O principal objetivo é projetar uma sinalização para o LAC que ofereça assistência a pessoas com necessidades especiais, criando um padrão de orientação e permitindo aos pacientes se localizarem facilmente dentro do laboratório.

Para o desenvolvimento do projeto, têm-se como base teórica disciplinas estudadas no Bacharelado em Design Gráfico na Universidade Jorge Amado (Salvador - BA), somado a conceitos e aplicações do Desenho Universal, Fisiologia e do Braille, implicando na redução do esforço necessário para os usuários do sistema acessar os ambientes.

A Metodologia adotada para desenvolver o projeto de sinalização constitui-se em diversas etapas, podendo ser segmentadas a depender do projeto, baseando-se em experiências práticas de diversos profissionais da área. Pretende-se organizar e compreender os processos envolvidos desde a concepção até a produção e instalação dos elementos que compõe o projeto de sinalização.

\section{DESENVOLVIMENTO}

\subsection{Problema de Estudo}

A sinalização atual do LAC apresenta diversos padrões visuais por meio de placas que foram compradas em avulso, sem a devida preocupação em definir um padrão visual interno e sem atentar aos pacientes com necessidades especiais que frequentam o local, carecendo de clareza e coerência visual. Isso provoca confusão no público-alvo, tanto na identificação do LAC, como na leitura espacial e locomoção interna.

Há uma urgente necessidade de se estabelecer um padrão de sinalização comum para o laboratório, propondo-o através de um novo design. Esse padrão deverá ser adotado tanto para a parte externa, como para a parte interna do laboratório. Essa sinalização pode proporcionar maior acessibilidade, conforto e autonomia para o público-alvo, além da clareza e coerência na consolidação da Identidade do LAC.

A sinalização desenvolvida para a empresa deve incorporar os conceitos de acessibilidade, utilizar elementos da marca da empresa e apresentar uma coerência visual em todas as aplicações com o intuito de ajudar as pessoas com necessidades especiais.

\subsection{Metodologia}

O referencial teórico com relação à metodologia voltada para projetos de sinalização ainda é bastante restrito. Então, através da proposição de uma metodologia baseada na experiência prática de diversos profissionais da área, pretende-se organizar e compreender os processos envolvidos desde a concepção até a produção e instalação dos elementos que 
compõe o projeto de sinalização, visando criar um conjunto de elementos eficiente do ponto de vista funcional, que seja facilmente compreendido e assimilado pelos usuários da edificação e que supra as necessidades informacionais dos usuários. Além disso, seja adequado ao espaço e à identidade visual da empresa.

A Metodologia adotada para desenvolver o projeto constitui-se em diversas etapas, enumeradas em oito tópicos. São eles:

1. Análise visual da atual sinalização, junto com a sinalização dos principais competidores, fazendo levantamento das necessidades;

2. Fazer mapeamento e planta baixa do local;

3. Teste de Orientabilidade com o público-alvo;

4. Teste de Compreensibilidade;

5. Desenvolver 3 conceitos iniciais de design;

6. 2 o teste de Compreensibilidade;

7. Selecionar o conceito final, desenvolvê-lo completamente, fazer protótipo e fazer o teste final com o público-alvo;

8. Implementação.

Vale ressaltar que essas etapas não são necessariamente lineares. De acordo com Itiro lida:

“O processo metodológico não é linear, ou seja, avanços realizados em uma etapa podem indicar a necessidade de retorno a etapas anteriores, com o objetivo de modificar algum aspecto já aprovado mas não confirmado como a melhor alternativa." (IIDA, 2007, pg 27.)

\subsubsection{Fase 1 - Análise Visual}

A análise visual consiste em estudar cada uma das placas já existentes no local, identificar seu tipo, onde foi instalado o texto escrito, o espaço (aberto ou fechado), a orientação, o tempo de exposição e os suportes utilizados para fixá-las. Fez-se o levantamento de todos os elementos que constituem a atual sinalização do laboratório. Na quadro 1 apresenta-se o resultado dessa análise.

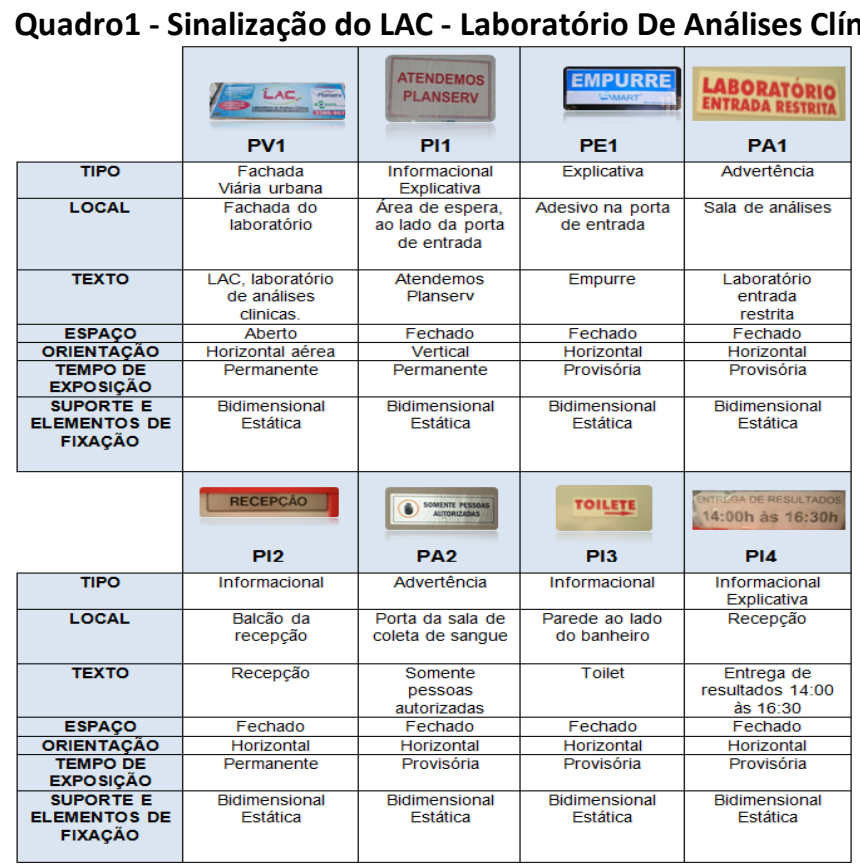

Fonte: Elaborado pelo autor, com base na pesquisa realizada. 
A partir dessa etapa pode-se concluir, primeiramente, que a sinalização existente apresenta-se em tamanho menor do que o ideal. Em geral, as placas são feitas com material inadequado, são frágeis e mais propícias à contaminação. A fachada, mesmo tendo dimensionamento adequado, não é notada de imediato devido à disposição imprópria com relação à rua (disposta em paralelo). Além disso, a mesma apresenta problemas quanto ao excesso de informações, tanto textuais como imagética.

É importante ressaltar que as placas devem ser sucintas, orientando os usuários de forma rápida e eficaz. Além disso, o material usado para o novo projeto deve ser resistente, duradouro e de fácil limpeza, evitando a contaminação dos pacientes. A matéria-prima deve ser maleável, pois se pretende aplicar o Braille em todas as placas, atendendo ao requisito de acessibilidade da contratação do projeto.

\subsubsection{Fase 2 - Mapeamento e Planta Baixa do Local}

A etapa de mapeamento visa conhecer de uma forma aprofundada todo o contexto em que o trabalho irá se desenvolver. Nesta etapa, todas as fontes de informação devem ser investigadas, a fim de que os dados referentes ao ambiente externo e interno do local sejam reunidos para análise. As condições do ambiente variam e é o ponto de partida para o desenvolvimento do sistema de sinalização.

A partir do estudo do ambiente, pode-se observar primeiramente que se trata de um ambiente de medidas restritas. Além de ter um tamanho reduzido, o laboratório foi segmentado de maneira bastante irregular, não aproveitando o espaço de forma adequada. Na Figura 1, apresenta-se a planta baixa do Laboratório de Análises Clínicas.

Figura 1 - Planta baixa do estabelecimento.

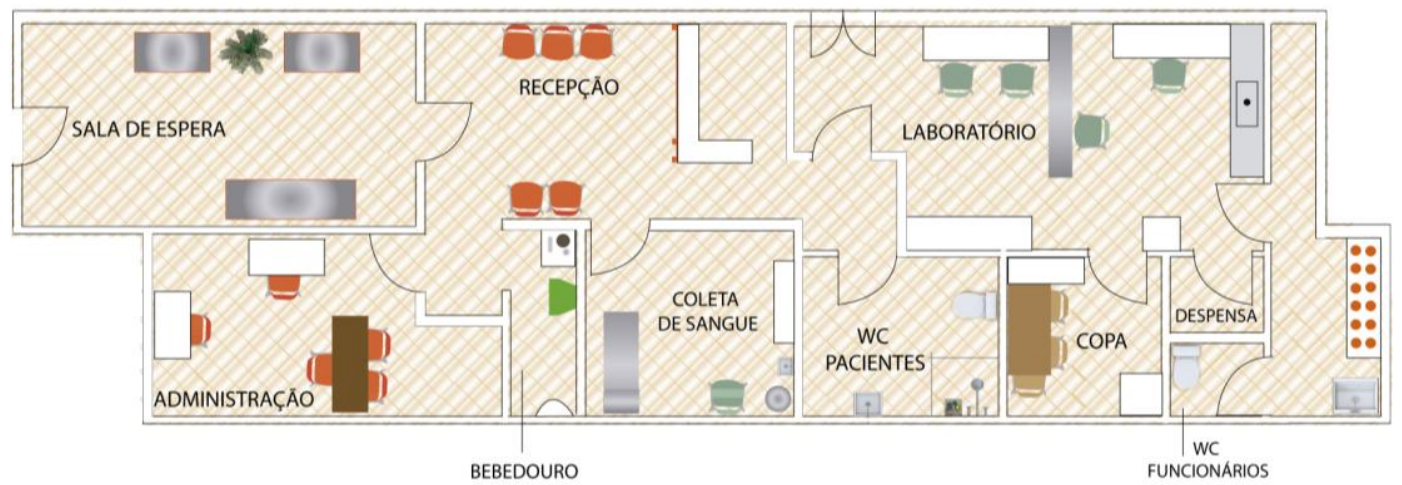

Fonte: Elaborado pelo autor, com base na pesquisa realizada.

O projeto de sinalização deverá considerar as restrições impostas pelo ambiente. Se tratando de um ambiente reduzido, serão projetadas placas em formato bidimensional, fixadas em portas e paredes, aproveitando ao máximo o espaço disponibilizado, priorizando as placas voltadas para a segurança.

\subsubsection{Fase 3 - Teste de Orientabilidade}

A orientabilidade consiste em um conjunto de variáveis espaciais que condicionam o desenvolvimento dos processos de orientação. Estar orientado significa saber onde se está no espaço e no tempo e poder definir seu próprio deslocamento. Esse processo ocorre através de informações do ambiente e é influenciada por experiências pessoais. 
Existem dois níveis de orientabilidade: A habilidade do indivíduo de representar, mentalmente, as características espaciais de um lugar e de situar-se dentro desta representação e o fenômeno dinâmico ligado ao movimento do indivíduo (reconhecimento de um local desconhecido).

Com o intuito de avaliar o fenômeno dinâmico da orientação espacial, foi realizado o teste de orientabilidade com seis pessoas. Ele consiste em um passeio guiado, onde os participantes deveriam executar cinco tarefas, que foram: localizar o LAC; pegar a ficha de atendimento; ir para a sala de coleta; ir até o banheiro e beber água.

Ao realizar as tarefas, foram analisados: sistematização e registro de comportamento, registro das verbalizações, mapa e descrição do caminhamento, registro das dificuldades e perguntas-chave (ex: quais os elementos do ambiente que você utilizou para reconhecer o caminho escolhido? Ou o que lhe auxiliou a tomar esta decisão?).

Após essa etapa, conclui-se que há uma grande necessidade de uniformidade na sinalização. Além disso, é necessário fazer intervenções ergonômicas com relação a:

- Setor administrativo - por uma placa de acesso restrito;

- Placas informando na recepção quais os serviços oferecidos;

- Sinalização externa perpendicular ao sentido dos carros;

- Agregar ao projeto sinalização indicativa para setores de maior uso dos pacientes, que são: a recepção, o banheiro, a sala de coleta e o bebedouro;

- Mudar sinalização da sala de coleta - Substituir a placa de "acesso restrito", por uma placa informacional ("sala de coleta").

- Indicativo para pegar a ficha;

- Necessidade de "Placas de sinalização de Biossegurança".

\subsubsection{Fase 4 - Teste de Compreensibilidade}

A fase 4 constitui-se na avaliação de compreensibilidade de símbolos, objetivando analisar a variação do repertório de símbolos dos usuários. A técnica consiste em escrever nas fichas o nome dos setores do local estudado e pedir ao usuário que faça um desenho e identifique-o, sendo realizado para o projeto com quinze usuários.

Após a realização das tarefas propostas, é realizada a avaliação da mesma, tendo a finalidade de quantificar quais os desenhos mais representados, adequando-os ao projeto. A partir dessas representações são escolhidos e trabalhados três símbolos, que servirão para o segundo teste de compreensibilidade, que será descrito mais adiante.

Foi possível notar a variação imagética dos usuários. No entanto, algumas áreas, como o banheiro, bebedouro e a recepção são representados de forma praticamente unânime, pois fazem parte do cotidiano da maioria dos usuários. É preciso ressaltar que algumas representações foram descartadas por não corresponderem ao repertório imagético da maioria.

\subsubsection{Fase 5 - Conceitos Iniciais de Design}

\subsubsection{Placas}

Pretende-se utilizar como base comunicativa o Desenho Universal, vertente do design que "visa atender melhor a maior gama de variações possíveis das características antropométricas e sensoriais da população." (NBR 9050, 1.3). Para isso, irá testar-se a eficácia não só da linguagem visual, como também a linguagem tátil e sonora, beneficiando as pessoas que possuem necessidades especiais. 
Como a maior parte do público alvo possui baixo grau de instrução, o foco na linguagem textual não é interessante, pois a sinalização deve transmitir a mensagem de imediato e na prática a mesma pouco interfere na leitura espacial deles. Para esse tipo de público, é necessário explorar bastante outras formas de linguagem.

A alternativa inicial desenvolvida foi fazer os símbolos vazados em alumínio através de traços simples, sobreposta a uma camada com a coloração, que varia a depender da mensagem a transmitir. Placas indicativas iriam sobrepor à cor verde (cor do novo logotipo) e as placas de advertência, à cor preta (Figura 2).

No entanto, esse conceito apresentou algumas falhas. Mesmo tendo uma boa parte de seus usuários analfabetos, a aplicação da linguagem verbal na sinalização continua sendo tão importante quanto à imagética, pois o uso de diferentes linguagens possibilita dúbias interpretações por parte do usuário.

A segunda alternativa desenvolvida consistia dispor o símbolo correspondente à cada representação do lado direito, ocupando a maior parte da placa, aplicando a esquerda a parte textual em sentido vertical, com a finalidade de enfatizar a linguagem visual, mas aplicar também a linguagem verbal.

Figura 2: Primeira e segunda alternativa para as placas, respectivamente.
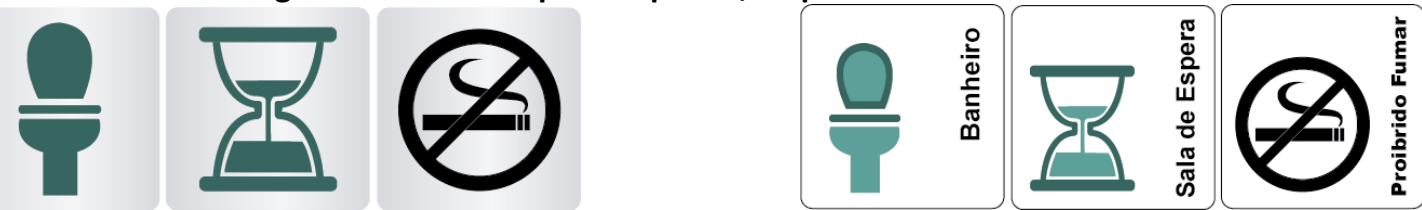

Fonte: Elaborado pelo autor, com base na pesquisa realizada.

O principal problema apresentado a essa alternativa foi à restrição para a aplicação do Braille. Além disso, notou-se que o texto posicionado na vertical, mesmo sendo agradável esteticamente, não é adequado para pessoas que possuem dificuldade de leitura (seja por acuidade visual por baixo grau de escolaridade).

A terceira alternativa buscou assimilar alguns conceitos válidos da segunda alternativa e fazer as modificações observadas, como a aplicação da linguagem verbal em sentido horizontal e espaço adequado para a aplicação do Braille.

Figura 3: Terceira alternativa para as placas
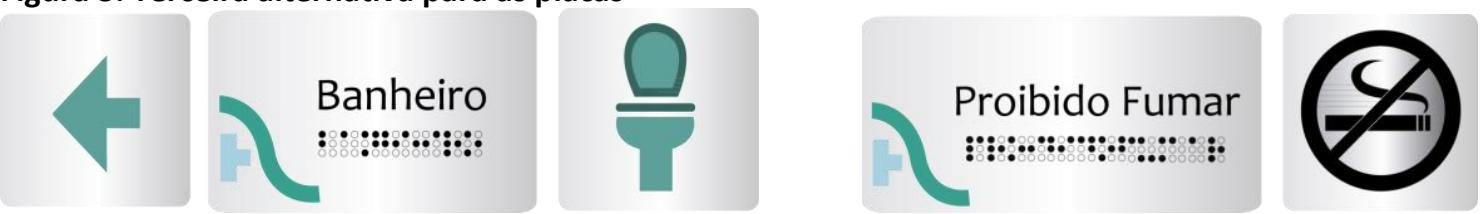

Fonte: Elaborado pelo autor, com base na pesquisa realizada.

A alternativa gerada apresentou-se mais eficiente, pois além de enfatizar a linguagem visual, inclui a linguagem verbal e o Braille, além de ser agradável esteticamente.

\subsubsection{Totem}

A alternativa inicial desenvolvida foi construir um " $\mathrm{L}$ " verde em PVC, com cerca de 1,5 m, servindo de suporte para uma placa de PVC com a Identidade Visual, fixada numa esquadria de alumínio, disposta em perpendicular com a via. Na página seguinte apresenta-se a figura da alternativa inicial (figura 4). 
Figura 4: Primeira alternativa de Totem

Fonte: Elaborado pelo autor, com base na pesquisa realizada.

No entanto, esse conceito apresentou algumas falhas. A aplicação desse totem na prática não se torna viável por se tratar de uma via estreita, atrapalhando a circulação do local. Além disso, tinha grandes chances do orçamento exceder o valor médio proposto.

A segunda alternativa foi desenvolvida a partir das observações das falhas da primeira alternativa gerada, visando solucionar o problema espacial da mesma. O suporte verde foi descartado, ficando apenas o suporte em PVC com o logotipo, fixado em uma esquadria de alumínio, utilizando o poste localizado em frente ao laboratório como base.

Figura 5: Segunda alternativa gerada para o Totem

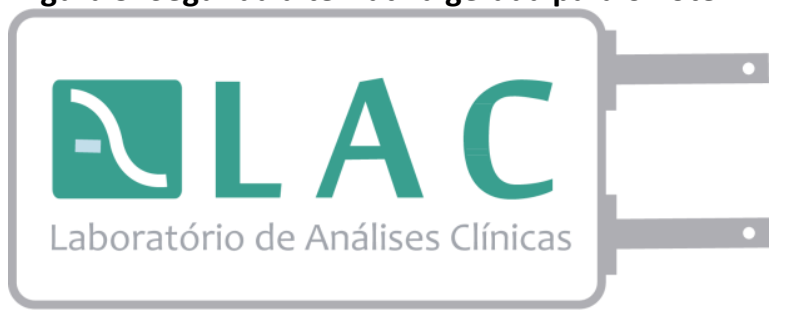

Fonte: Elaborado pelo autor, com base na pesquisa realizada.

A alternativa gerada é simples esteticamente, mas possui diversas vantagens. Além de solucionar o problema espacial e de usar menos recursos (barateando seu custo), utiliza de um elemento já existente (poste) como base, revertendo à ergonomia do objeto com relação ao LAC, que antes atrapalhava a visualização do mesmo.

\subsubsection{Piso Tátil}

A sinalização do piso tem como função orientar e avisar as pessoas cegas ou com baixa visão. Ela funcionará como uma trilha indicando o caminho desejado e deve também ser facilmente detectada pela bengala usada pelas pessoas com acuidade visual. Para tanto, será utilizado na cor cinza, contrastando com o chão do LAC, para atender também aos usuários portadores de baixa visão.

O piso tátil deve ser de material rígido, firme, estável e antiderrapante sob qualquer condição, atendendo aos requisitos específicos determinados pelas normas técnicas da Associação Brasileira de Normas Técnicas - ABNT.

\subsubsection{Fase 6 - Segundo Teste de Compreensibilidade}

O segundo teste de compreensibilidade consiste na escolha do símbolo que representará cada ambiente da sinalização. Seu objetivo é definir qual dos três símbolos escolhidos no primeiro teste de compreensibilidade mais se adéqua ao 
repertório do usuário do sistema. No LAC, optou-se pela participação de vinte pessoas no teste. A técnica consiste em escrever nas fichas o nome dos setores do local estudado e desenhar os três símbolos escolhidos no primeiro teste. É pedido ao usuário que escolha um dos três símbolos. A seguir apresenta-se o modelo das fichas:

Figura 6 - Modelo de fichas para o segundo teste de compreensibilidade.

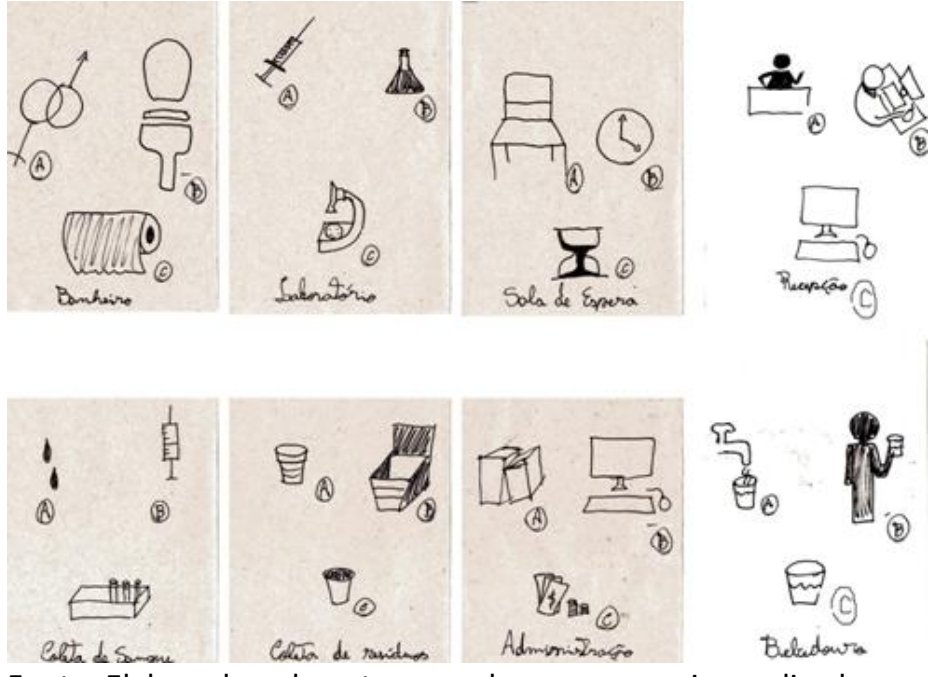

Fonte: Elaborado pelo autor, com base na pesquisa realizada.

Como resultado, as mais votadas foram: 0 vaso sanitário para representar o Banheiro, o computador para a Administração, o do tubo de ensaio para representar o Laboratório, o símbolo da cadeira para a Sala de Espera, a seringa para o local de Coleta de Sangue e a imagem do balcão e recepcionista mais simplificados para a Recepção.

Para o Bebedouro, não foi utilizado o símbolo do objeto em si por conta da possibilidade da mudança de modelos que o LAC pode fazer ao longo do tempo, correndo o risco de causar equívocos nos usuários do sistema. Então, os três símbolos utilizados neste teste foram: torneira com copo, um homem com um copo na mão, e um copo com água. Destes símbolos, a maioria votou no homem com um copo.

\subsubsection{Fase 7 - Avaliação do Protótipo}

A avaliação do protótipo consiste em produzir a alternativa gerada em material inferior ao da implementação final. A partir daí, serão observadas reações dos usuários e caso necessário, serão feitas as alterações necessárias.

Toda a sinalização interna foi produzida em papel sulfite, tamanho $21 \times 9 \mathrm{~cm}$, colado sobre papelão e fixado em toda a ambientação interna do laboratório, instalada entre 90 e 110 centímetros de altura do chão, com base na norma da ABNT, a NBR 9050 (Norma Técnica Brasileira voltada para Acessibilidade).

Figura 7- Avaliação do protótipo.

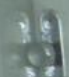

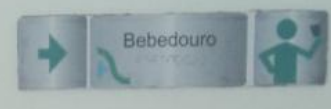

Fonte: Elaborado pelo autor, com base na pesquisa realizada. 
Após a implantação, foi feita a análise comportamental a partir de observações e do preenchimento de um questionário cujo trinta e seis pessoas participaram. 0 questionário possuía os seguintes itens: Nome, Idade, Escolaridade, Bairro onde mora, Sexo (feminino ou masculino), "Porque optou pelo LAC?", Pontos positivos, Negativos, "O que achou da sinalização do LAC?" Comentário e Assinatura.

A partir das observações e dos resultados obtidos no questionário, foi notado que a sinalização agradou praticamente todos os usuários, que julgaram a sinalização criativa, organizada e de fácil identificação. O tamanho estava adequado para a necessidade dos pacientes, sendo notada inclusive pelos mais idosos. Além disso, as setas direcionais em vários setores mostraram-se eficazes em auxiliar na orientação dos pacientes.

Porém, durante os testes, os usuários tiveram um pouco de dificuldades para ler as placas devido à altura muito baixa, obrigando todos a se curvarem. Isso tornaria a leitura do Braille difícil e lenta, sendo necessário então o reposicionamento das placas.

\subsection{Implementação}

Para fachada do laboratório optou-se por utilizar a lona grossa, pois permite trabalhar com impressão digital, é um material de fácil limpeza e manutenção, com durabilidade que varia de um a dois anos quando exposta a fenômenos climáticos. Para fixação, serão utilizadas esquadrias de alumínio por serem resistentes a corrosão, atributo que se complementa com tratamentos de superfície, como anodização ou pintura.

Os pisos táteis propostos serão produzidos em Nylon Industrial, o que os torna flexíveis, recicláveis, e resistentes. A fixação dos pisos táteis será com cola Sista FT 1012, conforme pesquisa feita no fornecedor Andaluz Acessibilidade, empresa brasileira especializada em produtos para deficientes visuais.

Para sinalização interna do LAC, serão utilizadas chapas planas de alumínio anodizado (processo que retarda a oxidação), ser um material leve, resistente, durável, maleável (quesito fundamental para o projeto, pois será aplicado o braille através de relevo alto) e por ser mais econômico em comparação a outros metais. $O$ alumínio também é o mais indicado para o manuseio, pois é possível fazer uma esterelização periodicamente, evitando a contaminação dos pacientes. Como o braille será aplicado nas placas, o contato manual será constante, fazendo- se necessária os processos de limpeza citados anteriormente.

Para fixação das placas, será utilizada fita adesiva de alto poder de fixação, aplicada nas extremidades da superfície. Para dispor as informações a serem sinalizadas nas placas será utilizado uma aplicação impressa em vinil sobre uma de suas superfícies.

A tipografia utilizada no projeto é a Arial, por ser uma fonte bastão (sem serifa), corpo 79 , beneficiando usuários que possuem acuidade visual, sendo aplicada em caixa alta e baixa, otimizando o tempo de leitura dos pacientes e aplicadas na cor preta, por haver um maior contraste com a coloração do alumínio.

\subsection{Orçamento}

No projeto de sinalização do LAC, ficou a cargo das designers apresentarem ao cliente, junto com o anteprojeto, uma planilha de custos de investimento e de produção, previamente, solicitada aos setores da empresa e aos fornecedores capacitados para a execução de cada etapa, e a depender do andamento do projeto, fazer os reajustes necessários no orçamento. Na página seguinte apresentam-se os valores orçados para a confecção do projeto. 
Quadro 2 - Planilha orçamentária.

\begin{tabular}{|c|c|c|c|c|}
\hline & MATERIAL & MEDIDAS & \multirow{2}{*}{\multicolumn{2}{|c|}{$\begin{array}{l}\text { CUSTO } \\
\text { R\$ } 480,00 \text { (Quatrocentos e } \\
\text { oitenta reais), impressão + } \\
\text { montagem + instalação. }\end{array}$}} \\
\hline Fachada do laboratớrio & $\begin{array}{l}\text { Impressão em lona com } \\
\text { acabamentoem perfis de } \\
\text { alumínio }\end{array}$ & $2,50 \times 1,30 \mathrm{~cm}$ & & \\
\hline \multirow[t]{2}{*}{ Placas de orientação } & \multirow{2}{*}{$\begin{array}{l}\text { Impressão direta no } \\
\text { alumínio, com } \\
\text { utilização de três cores } \\
\text { e braile em alto relevo. }\end{array}$} & $\begin{array}{l}\text { Placas com escritae } \\
\text { braile: } 25 \times 10 \mathrm{~cm} .\end{array}$ & $\begin{array}{l}\text { Placas } \\
\text { maiores = } \\
\text { R\$ } 40,00 \mathrm{a} \\
\text { unidade. }\end{array}$ & \multirow{2}{*}{$\begin{array}{l}\mathrm{R} \$ 40,00 \times 16= \\
\mathrm{R} \$ 640,00 \\
\mathrm{R} \$ 25,00 \times 20= \\
\mathrm{R} \$ 500,00 \\
\text { Total: } \mathrm{R} \$ 1140,00 \\
\text { (mil cento } \\
\text { quarenta reais). }\end{array}$} \\
\hline & & $\begin{array}{l}\text { Placas com ilustração } 10 \\
x 10 \mathrm{~cm} .\end{array}$ & $\begin{array}{l}\text { Placas } \\
\text { menores= } \\
\text { R\$25,00a } \\
\text { unidade. }\end{array}$ & \\
\hline Fita VHB & $\begin{array}{l}\text { Fixação das placas de } \\
\text { alumínio. }\end{array}$ & 12 metros & \multicolumn{2}{|c|}{$\mathrm{R} \$ 17,00$ (Dezessete reais). } \\
\hline Piso tátil & $\begin{array}{l}\text { Aderência ao chão, } \\
\text { borracha sintética } \\
\text { alerta e direcional. }\end{array}$ & $25 \times 25 \mathrm{~cm}$ & \multicolumn{2}{|c|}{$\begin{array}{l}\mathrm{R} \$ 3,60 \text { un. } \\
\mathrm{R} \$ 14,40 \text { o metro quadrado, } 4 \\
\text { placas. } R \$ 14,40 \times 16 \\
\text { metros } R \$ 230,40\end{array}$} \\
\hline Totem & $\begin{array}{l}\text { Impressão em PVC, } \\
\text { dupla face, com } \\
\text { acabamento em perfis } \\
\text { de alumínio. }\end{array}$ & $60 \times 30 \mathrm{~cm}$ & \multicolumn{2}{|c|}{$\begin{array}{l}\text { RS } 140.00 \text { (Cento e quarenta } \\
\text { reais) Impressão + montagem }\end{array}$} \\
\hline & & & \multicolumn{2}{|c|}{ Custo total = RŞ 2007,40 } \\
\hline
\end{tabular}

Fonte: Elaborado pelo autor, com base na pesquisa realizada.

\subsection{Manequins Antropométricos}

Na concepção de projetos de sinalização é importante considerar as diferentes potencialidades e limitações do indivíduo. A abordagem ergonômica, associada aos dados obtidos a partir da antropometria estática, dinâmica e funcional, torna-se fundamental para a definição dos parâmetros antropométricos e dos indicadores técnicos de acessibilidade.

Em geral, pessoas com deficiências têm limitações para desenvolver tarefas e manipular objetos em ações simultâneas. Pessoas com essa característica se deslocam, em geral, com a ajuda de equipamentos auxiliares: bengalas, muletas, andadores, cadeiras de rodas, ou até mesmo com a ajuda de cães adestrados, no caso de pessoas cegas. Portanto, é necessário considerar o espaço de circulação com os equipamentos que as acompanham.

\subsubsection{Campo De Visão}

O campo de visão é a porção do espaço, medida em magnitude angular, que dope ser vista quando a cabeça e os olhos estão imóveis. Este campo de visão central é denominado "campo binocular" e é cerca de $60^{\circ}$ em cada direção.

Para a implementação dos elementos da sinalização, foi preciso calcular o campo de visão a partir do ângulo mais baixo de visão do maior homem, o maio ângulo de visão da menor mulher e o maior ângulo de visão do cadeirante. A partir dos resultados obtidos, escolhe-se a altura mais adequada, respeitado as limitações arquiteturais do ambiente. 


\subsubsection{Fachada e Totem}

Como o banner tem a função de comunicar a distâncias maiores, logo o campo de visão aumenta, sendo posto a $2,80 \mathrm{~m}$ do chão. Já o totem foi posto em perpendicular com relação à rua, a 2,50m do chão, tornado possível a visualização das pessoas que circulam pelas vias, estando em um meio de transporte ou sendo pedestres.

Figuras 8 e 9 - Manequins atropométricos do campo de visão da Fachada e do Totem, respectivamente.

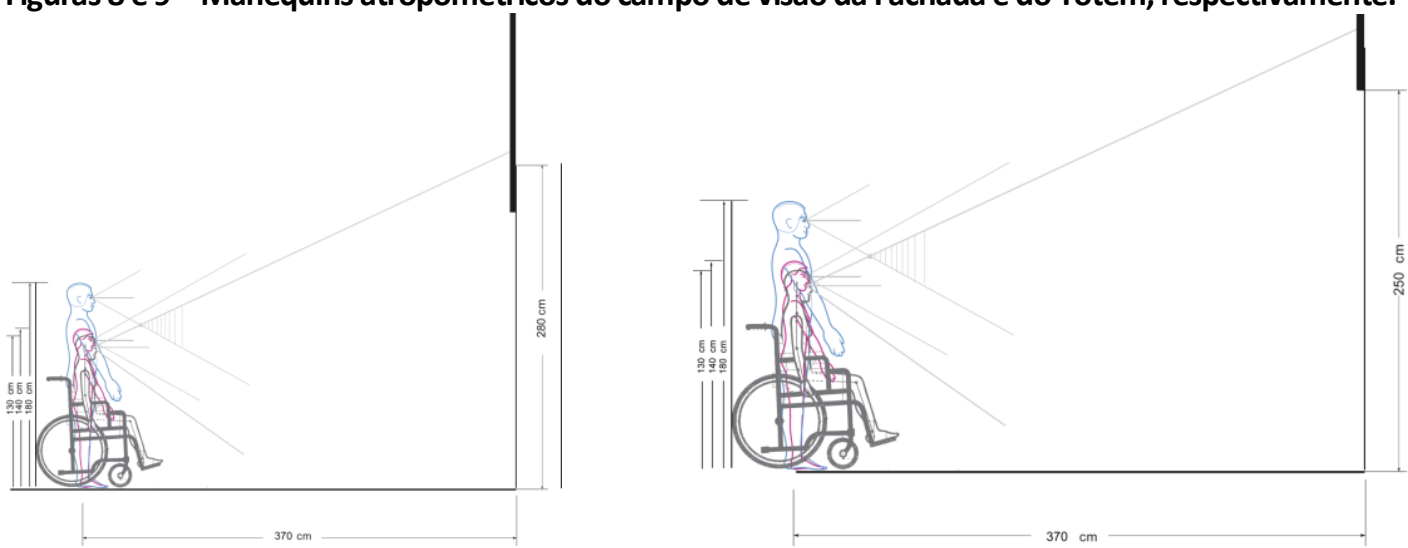

Fonte: Elaborado pelo autor, com base na pesquisa realizada.

\subsubsection{Placas}

Baseando-se no resultado dos testes, a altura das placas foi modificada para melhor atender às necessidades das pessoas com acuidade visual, posicionadas a $130 \mathrm{~cm}$ do chão e fixadas no meio da porta, porque assim tornou-se mais fácil a identificação das salas e para facilitar a leitura do Braille.

Figura 10 e 11 - Área de visão e de alcance das placas internas. Fonte: Arquivo do próprio autor.
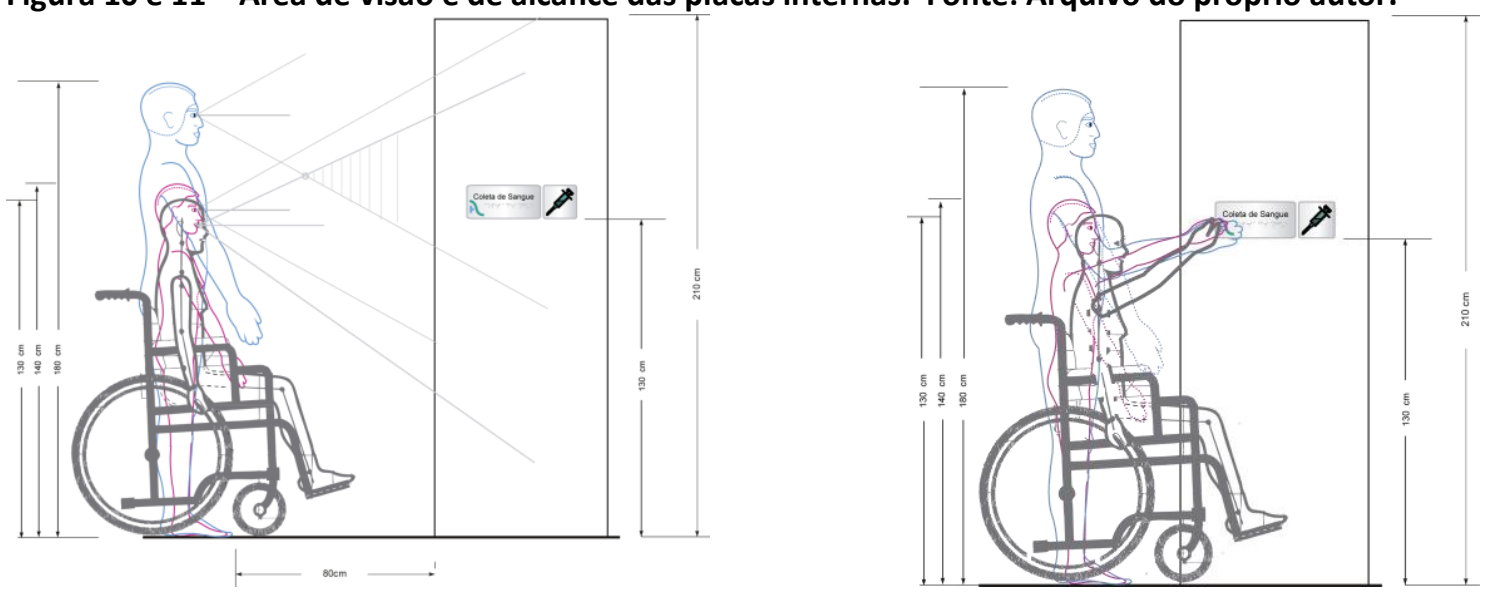

Fonte: Elaborado pelo autor, com base na pesquisa realizada.

\subsection{Resultado Final - Simulação}

Figura 12, 13 e 14- Simulação da implemetação do totem, fachada e placas internas, respectivamente.
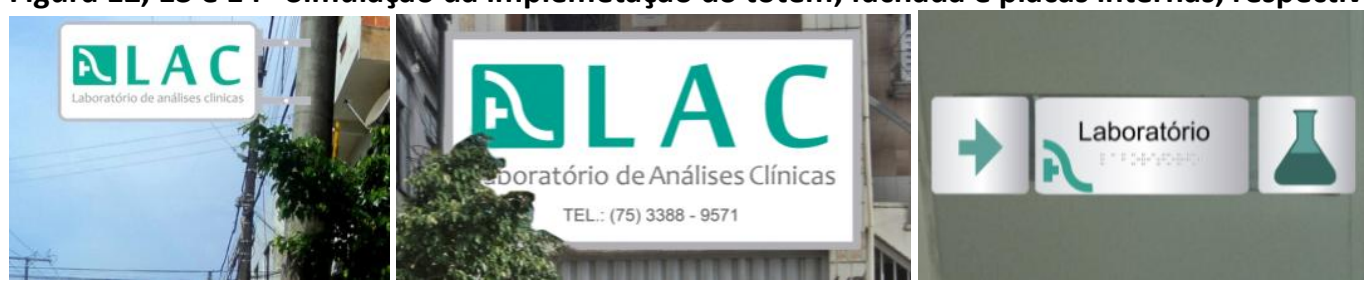

Fonte: Elaborado pelo autor, com base na pesquisa realizada. 


\section{CONCLUSÃO}

Através do presente trabalho foi projetado um sistema de sinalização que prioriza o acesso de pessoas com necessidades especiais. Com isso, objetivou-se que os pacientes do laboratório se integrassem ao convívio social, independente das suas diferenças, utilizando os setores de forma autônoma.

Ao projetar um sistema de sinalização, deve-se planejar como orientar as pessoas a se deslocarem no menor espaço de tempo possível. A compreensão da diversidade cognitiva do público-alvo e como a informação é transmitida, recebida e decodificada em cada um desses grupos é fundamental para a sinalização.

As etapas do projeto e os testes permitiram o entendimento de como as pessoas com necessidades especiais percebem o ambiente em sua volta e de que forma a sinalização daria independência para circulação segura nos setores do LAC.

Durante o desenvolvimento do projeto, percebeu-se que embora lugares sem acessibilidade não incomodem indivíduos que não tem necessidades especiais, a eliminação dessas barreiras favorece a todos. Um ambiente acessível oferece qualidade de vida, segurança, interação e boa convivência tanto para as pessoas que possuem algum tipo de necessidade especial, como para quem não possui.

Todo o exposto é uma contribuição na fundamentação de demais ações de pesquisa e no despertar da consciência inclusiva no momento do desenvolvimento de projetos por parte dos profissionais das diversas áreas do Design.

\section{REFERÊNCIAS}

Associação Brasileira de Normas Técnicas. NBR 9050. Edição 31/05/2004.

BATIZ, Eduardo. Fisiologia do trabalho. Rio Grande do Sul: PUC, 2003.

FERREIRA, Mario; ANTÔNIO, Carlos. Ergonomia: conceitos, histórico e aplicações. Rio Grande do Sul: PUC, 2009.

IIDA, Itiro. Ergonomia: Projeto e produção. São Paulo, Editora Blucher, 2007.

JURY, Davi. O que é tipografia. São Paulo: Editorial Gustavo Gili, 2007

LAKATOS, Eva Maria e MARCONI, Marina de Andrade. Metodologia do trabalho Científico. São Paulo: Atlas, 1992.

MORAES, Anamaria; MONT'ALVÃO, Claudia. Ergonomia: conceitos e aplicações. Rio de Janeiro: Editora iUser, 2003.

NEUFERT, Ernst. Arte de Projetar em Arquitetura. São Paulo: Editora Saraiva, 1996.

NIEMEYER, Lucy. Elementos da semiótica aplicados ao design. São Paulo: Editora 2AB, 2010.

PHILLIPS, Peter. Briefing: a gestão do projeto de design. Tradução Itiro lida. São Paulo: Editora Blucher, 2008.

PRADO, Adriana; LOPES, Maria; OMSTEIN, Sheila. Desenho Universal: Caminhos da acessibilidade no Brasil. São Paulo: Editora Annabule: 2010

SALTZ, Ina. Design e Tipografia: 100 Fundamentos Do Design Com Tipos. São Paulo: Editora Blucher, 2010.

VIERA, Patrícia Cunha, PEDRUZI, Letícia Fonseca. Sistema de sinalização acessível em Braille. São Paulo, InfoDesign, 2011. 